\title{
Will the Convention on Biological Diversity put an end to biological control?
}

\author{
Joop C. van Lenteren ${ }^{1}$, Matthew J. W. Cock ${ }^{2}$, Jacques Brodeur ${ }^{3}$, Barbara I. P. Barratt ${ }^{4}$, Franz Bigler ${ }^{5}$, \\ Karel Bolckmans ${ }^{6}$, Fabian Haas ${ }^{7}$, Peter G. Mason ${ }^{8}$ \& José Roberto P. Parra ${ }^{9}$
}

\author{
${ }^{1}$ Laboratory of Entomology, Wageningen University, P.O. Box 8031, 6700 EH Wageningen, The Netherlands. joop.vanlenteren@wur.nl \\ ${ }^{2}$ CABI Europe-Switzerland, Rue des Grillons 1,CH-2800 Delémont, Switzerland. m.cock@cabi.org \\ ${ }^{3}$ Institut de Recherche en Biologie Végétale, Université de Montréal, 4101, rue Sherbrooke Est, H1X 2B2 Montréal, Québec, Canada. \\ jacques.brodeur@umontreal.ca \\ ${ }^{4}$ AgResearch Limited, Invermay Agricultural Centre, Puddle Alley, Private Bag 50034, Mosgiel, New Zealand. barbara.barratt@agresearch.co.nz \\ ${ }^{5}$ Agroscope Reckenholz-Tänikon Research Station ART, Reckenholzstrasse 191, CH-8046 Zurich, Switzerland. franz.bigler@art.admin.ch \\ ${ }^{6}$ Koppert B.V., Veilingweg 14, Postbus 155, 2650 AD Berkel en Rodenrijs, The Netherlands. kbolckmans@koppert.nl \\ ${ }^{7}$ Icipe, Duduville Campus, Kasarani, P.O. Box 30772 - 00100, Nairobi, Kenya. fhaas@icipe.org \\ ${ }^{8}$ Agriculture and Agri-Food Canada, Research Centre, K.W. Neatby Building, 960 Carling Avenue, K1A 0C6, Ottawa, Ontario Canada. \\ peter.mason@agr.gc.ca \\ ${ }^{9}$ Departamento de Entomologia e Acaralogia, ESALQ, Universidade de São Paulo. Caixa Postal 09, 13418-900 Piracicaba-SP, Brazil. \\ jrpparra@esalq.usp.br
}

\begin{abstract}
Will the Convention on Biological Diversity put an end to biological control? Under the Convention on Biological Diversity countries have sovereign rights over their genetic resources. Agreements governing the access to these resources and the sharing of the benefits arising from their use need to be established between involved parties. This also applies to species collected for potential use in biological control. Recent applications of access and benefit sharing principles have already made it difficult or impossible to collect and export natural enemies for biological control research in several countries. If such an approach is widely applied it would impede this very successful and environmentally safe pest management method based on the use of biological diversity. The International Organization for Biological Control of Noxious Animals and Plants has, therefore, created the "Commission on Biological Control and Access and Benefit Sharing". This commission is carrying out national and international activities to make clear how a benefit sharing regime might seriously frustrate the future of biological control. In addition, the IOBC Commission members published information on current regulations and perceptions concerning exploration for natural enemies and drafted some 30 case studies selected to illustrate a variety of points relevant to access and benefit sharing. In this article, we summarize our concern about the effects of access and benefit sharing systems on the future of biological control.
\end{abstract}

KEYWORDS. ABS; biological control; CBD; exotic natural enemies; invasive species; legislation; non-monetary benefit sharing.

RESUMO. Poderá a Convenção em Diversidade Biológica por um fim no Controle Biológico? Baseando-se na Convenção sobre Diversidade Biológica, os países têm soberania sobre seus recursos genéticos. Acordos que governam o acesso a tais recursos e o compartilhamento dos benefícios provenientes do seu uso precisam ser estabelecidos de comum acordo com as partes envolvidas. Isto também é aplicável a espécies coletadas com uso potencial em controle biológico. Recentes aplicações dos princípios de introdução e compartilhamento dos benefícios têm tornado difícil, ou mesmo impossível, coletar e exportar inimigos naturais em muitos paises para pesquisas em controle biológico em muitos países. Como esta é uma medida amplamente utilizada, tais procedimentos poderão impedir este bem sucedido e ambientalmente seguro método de manejo de pragas, baseado no uso da diversidade biológica. A Organização Internacional para Controle Biológico de Plantas e Animais Nocivos (IOBC) criou a "Comissão em Controle Biológico e Introdução e Benefícios Mútuos" para estudar o assunto. Tal comissão está desenvolvendo atividades nacionais e internacionais para esclarecer como o regime de compartilhamento de benefícios pode prejudicar seriamente o futuro do controle biológico. Além disto, membros da Comissão da IOBC publicaram informações sobre regulamentos atuais e suas opiniões relacionadas à exploração de inimigos naturais, listando cerca de 30 casos para ilustrar os pontos relevantes para a introdução e compartilhamento de benefícios. No presente artigo, é sumarizado o ponto de vista dessa comissão na IOBC sobre os efeitos dos sistemas de introdução e compartilhamento para o futuro do Controle Biológico.

PALAVRAS-CHAVE. CDB; compartilhamento de benefícios não lucrativos; controle biológico; espécies invasoras; inimigos naturais exóticos.

Under the Convention on Biological Diversity (CBD; see www.cbd.int) countries have sovereign rights over their genetic resources. Agreements governing the access to these resources and the sharing of the benefits arising from their use need to be established between involved parties (i.e. Ac- cess and Benefit Sharing (ABS)). This also applies to species collected for potential use in biological control. Recent applications of CBD principles have already made it difficult or impossible to collect and export natural enemies for biological control research in several countries. If such an 
approach is widely applied it would impede this very successful and environmentally safe pest management method based on the use of biological diversity.

The CBD was required to agree to a comprehensive Access and Benefit Sharing process in 2010, in preparation for which the IOBC (International Organization for Biological Control of Noxious Animals and Plants) Global Commission on Biological Control and Access and Benefit Sharing prepared and published two documents (a report for FAO and a scientific paper for BioControl) (Cock 2009, 2010) to make clear how an $\mathrm{ABS}$ regime might seriously frustrate the future of biological control.

The report prepared at the request of FAO was to summarize the past and current situation regarding the practice of biological control in relation to the use and exchange of biological control agents (BCAs) and ABS. The IOBC Commission members collected information on current regulations and perceptions concerning exploration for natural enemies and helped draft some 30 case studies selected to illustrate a variety of points relevant to ABS, ranging from the difficulties that ABS already represents, to practical examples of situations where application of ABS is not straightforward, to successes and the implications for ABS sharing. In October 2009, the report, which is unique in its overview of the current state of affairs in biological control, was published by FAO (Cock et al. 2009). A summary of the report is presented below and a pdf file of the report can be downloaded from ftp://ftp.fao.org/docrep/fao/meeting/017/ ak569e.pdf.

The main conclusions of the report were presented by IOBC Global (www.IOBC-Global.org) during an FAO meeting on the issue of ABS in October 2009. IOBC representatives observed that country representatives present at the FAO meeting frequently had not realized (a) how generally biological control was applied in almost all countries worldwide, (b) that in classical biological control no direct profits were accrued by the biological control community performing the work, (c) how little money was involved in commercial biological control, and (d) how dependent biological control workers are on exotic natural enemies. Several country representatives requested more information and documentation about biological control.

The IOBC report to FAO minimized political statements, to focus on a factual summary. The IOBC Commission on Biological Control and ABS thought it was essential to present these issues to the biological control community, as an important part of this community is still unaware of, or just beginning to understand the possible implications of ABS. Therefore, the Commission wrote a forum article for the journal BioControl, entitled "Do new Access and Benefit Sharing procedures under the Convention on Biological Diversity threaten the future of Biological Control?" (Cock et al. 2010). The full text of the paper, including additional material, can be downloaded from www.springer.com/life+sci/entomology/ journal/10526 or requested from the authors of this article. This paper deliberately takes a more political stance and takes an advocacy role on behalf of the IOBC community. We would like to stress the importance of the final sentences of this paper: "Finally, we urge biological control (BC) leaders in each country to join forces and get in touch with the ABS contact point for their country as soon as possible, and raise the issues surrounding the practice of $\mathrm{BC}$ and $\mathrm{ABS}$, using local examples when appropriate, so their national delegates to the ABS discussions in 2010 are appropriately informed. Only if the $\mathrm{BC}$ community of practice gets involved in the discussions now, can they expect their needs to be taken into consideration."

The IOBC Commission will continue its work with the drafting of a document describing best practices for ABS in relation to biological control including guidelines for joint research that are equitable, but not restrictive.

The IOBC report to FAO "The use and exchange of biological control agents for food and agriculture". The report sets out to summarize the past and current situation regarding the practice of biological control in relation to the use and exchange of genetic resources relevant for BCAs. It considers the two main categories of biological control: classical and augmentative. Allowing access to BCAs for use in another country imposes no risk of liability to the source country. Local scientific knowledge about habitats, fauna and flora, can be helpful for locating suitable sites for surveys and collections. Biological control is a research-based activity that requires access to genetic resources but one that is not expected to generate large monetary returns. It is not the practice in the biological control sector to patent biological control organisms.

The Research Process and Opportunities for Benefit Sharing. Preliminary surveys for the target pest and its natural enemies will often need to be carried out in several countries. These surveys offer limited opportunities for financial benefit sharing, but benefit the source country through provision of training in survey methods, joint surveys, capacity building and information generated to better understand biodiversity. Specimens of pests and natural enemies would normally need to be exported for identification and taxonomic studies.

Detailed studies on natural enemies to assess their potential as BCAs must in part be carried out in the source country, while host-specificity studies involving plants or animals not naturally occurring in the source country would best be carried out in quarantine in the target country or in a third country. It is this stage of a biological control programme that provides great scope for collaboration, shared research and capacity building. In comparison, there is relatively little scope for routinely sharing research with the source country during the BCA release stage.

In source countries, local partners are essential to carry out biological control surveys and research. When added to the moral obligation in the spirit of ABS, there is a compelling case for local partnerships. Some of these local partners will become the leaders in developing biological control options for their country in the future. 
The Implementers. Two main groups of producers are involved in augmentative biological control: commercial and centralized. The former are independent companies who produce and sell BCAs to users. Such companies have mostly operated in developed countries, but new ones are increasingly common globally, particularly supporting cash crop production in middle-income countries. The centralized production units are government- or industry-owned and produce natural enemies for a particular niche, normally large-scale agriculture or forestry, or the natural environment which are either provided free or sold to users. In the case of classical biological control, those who implement it are normally national agencies or programmes. Classical biological control in developing countries is often carried out with the financial support of international development agencies and technical support of implementation agencies.

The Benefits to Users and Their Customers. In the context of agriculture and forestry, the main beneficiaries of classical biological control are the farmers who have their pest problems reduced without necessarily actively using BCAs, which by spreading and reproducing naturally contribute to the public good. The reduced crop losses from pests lead to improved food security and improved livelihoods. Farmers in all parts of the world have benefited from this. Consumers also benefit from reduced use of pesticides, and hence lower pesticide residues in food. Thus, classical biological control is in the domain of public good, as the benefits reach all who grow and benefit from the crop, without requiring them to intervene. The use of augmentative and classical biological control enables producers to reduce pesticide use and residues to meet the high standards of profitable northern export markets, resulting in job creation amongst the growers and a very significant influx of foreign exchange in developing countries.

To make augmentative biological control products available in developing countries it is necessary to establish massproduction facilities, which create job opportunities. Also important is the creation or retention of jobs in agricultural production systems dependent upon augmentative or classical biological control.

Biological control also addresses invasive alien species that are problems in agriculture, forestry and the environment. Biological control is an cost-effective tool to tackle alien pest problems. Furthermore, biological control is environmentally friendly and generally does not lead to a reduction of biodiversity which is often observed when chemical pesticides are used.

The Extent of Use of Biological Control. At least 7000 introductions of BCAs involving almost 2700 BCA species have been made. The most widely used BCAs have been introduced into more than 50 countries. BCAs from 119 different countries have been introduced into 146 different countries. High-income countries have implemented classical biological control the most and have also been the main source of BCAs. Low-income countries have contributed slightly more BCAs than they have received.

In augmentative biological control, more than 170 species of natural enemies are produced and sold, but some 30 species make up more than $90 \%$ of the market worldwide. There is a trend in augmentative biological control to first look for indigenous natural enemies when a new, even exotic, pest develops.

Once a BCA has been used successfully in one country the opportunity has often been taken to repeat that success in other countries through redistribution of the BCA. Developing countries have benefited from access to such tested BCAs because research and implementation was carried out by developed countries. For example, the work of developed countries with subtropical and tropical regions, e.g. Australia and the USA, has directly benefited developing countries in the tropics and subtropics. Usually BCAs for redistribution have been re-collected in the target country rather than the original source country.

Control of Genetic Resources and Opportunities for Profit. In the case of classical biological control, a national or international research institute usually carries out the research, but once established, a BCA ceases to be under its control. The agent breeds and ideally contributes effectively to management of the target pest. The BCA will disperse to the geographic range limits to which it is suited, often including other countries. The classical biological control ethos is to establish a free-of-charge public good. The sector has traditionally made no use of intellectual property rights to regulate access to, or use of, classical BCAs. All knowledge generated is put into the public domain, and other countries are encouraged to take advantage of this new BCA. Benefits to farmers, consumers, and the local economy, do not return to the research institute or development agency in monetary form.

In the case of augmentative biological control, a company might survey for a useful new BCA to control a particular pest. They research it and develop rearing, distribution and release methods at their own expense. The augmentative biological control company then sells it to growers or other customers, generating profits for the company. Farmers who paid for the BCA benefit from effective pest control and improved yields, growing food without pesticides with implications for their own health, and the price they can obtain for their produce. The customers who buy the food are able to get healthy food at an acceptable price. It is not the practice in the augmentative biological control sector to use patents for BCAs, so anyone can collect and use the agents from nature. Augmentative biological control companies may establish patents on rearing processes, but more usually handle this by keeping the relevant know-how secret.

Worldwide, some 30 larger commercial producers of augmentative BCAs are active, of which 20 are located in Europe. In addition to the larger producers, some 100 small commercial producers are active, employing fewer than five people. 
The total market for augmentative biological control natural enemies at end-user level in 2008 was estimated at about US\$100-135 million. With an average net profit margin of around $3-5 \%$, the total commercial augmentative biological control industry profit is under US\$15 million per year. Augmentative biological control is a small activity undertaken by small and medium-sized enterprises and with modest profits.

Regulation of Introduction of Biological Control Agents. Over the last 20 years, the introduction of BCAs has increasingly followed international or national legislation. ISPM3 (International Standards for Phytosanitary Measures No. 3) of the IPPC (International Plant Protection Convention) sets out the responsibilities of the different players, but does not address the issue of ABS.

Since the earliest days of biological control, there has been a community of practice based on free multilateral exchange of BCAs, rather than bilateral exchange or defined benefit sharing agreements. Countries are both providers and users of BCAs. It has usually made good practical sense to collaborate with a research organization in a (potential) source country, and as the need for more detailed risk and environmental impact assessment studies has grown, the need for collaborative research in the source country has grown. Conversely, there is a general trend for access to genetic resources, including BCAs, to become increasingly restrictive, for a variety of reasons, including $\mathrm{ABS}$ regulations and, in the case of biological control, phytosanitary legislation. The existing multilateral free exchange ethos and effective global networking of biological control practitioners is a foundation that deserves special consideration with regard to ABS.

New legislation has been and is being introduced in some countries regarding access to genetic resources. If legislation is not designed to accommodate biological control, it becomes a very difficult and challenging process for both international researchers and their national collaborators. In the short term, this legislation will remain in place with obligatory compliance. There is a risk that new international ABS legislation not tailored to the needs of the sector will add another layer of regulation to the research, which is likely to slow the process.

The arrival of a new invasive alien pest in a country can be economically or environmentally devastating. In such cases, there is an argument that an emergency response may be needed before irreversible harm is done. That emergency response could be classical biological control. In such cases fast-track procedures for access to genetic resources should be anticipated and facilitated.

User Perspectives. The attitudes and views of biological control players reflect a mixture of positions regarding ABS. Much of the classical biological control community has been unaware of the potential of ABS to affect its activities, although the pragmatic need for a good local collaborator is recognized. However, there is now growing awareness of ABS policies and the need for continued exchange of BCAs so that biological control and the resultant public good will be guaranteed.
The implementers of classical biological control have long been aware that classical biological control does not bring them cash benefits. It is against the classical biological control ethos, which is based on government and donor financing to create a free-of-charge public good. Furthermore, there is no pathway or mechanism to collect monetary benefits from the beneficiaries, such as smallholder farmers. For this reason, forms of non-monetary benefit sharing are appropriate, based around shared research activities and capacity building.

On the other hand, the augmentative biological control community has been more aware of the issues, perhaps because augmentative biological control does generate some modest commercial profits. Larger augmentative biological control producers, such as members of the International Biocontrol Manufacturers Association (IBMA) and the Association of Natural Biocontrol Producers (ANBP), are willing to consider benefit sharing in the form of knowledge sharing, training, provision of natural enemies, and in other ways. In the event that a natural enemy obtained from a source country becomes a commercially successful BCA, some augmentative biological control producers foresee that payment of 'royalties' to the country of origin might be possible, but if the industry had to pay for access to each natural enemy collected, they would anticipate not being able to continue with this type of work. On balance, these producers believe that benefits from shared activities and capacity building would be a more realistic approach, given the relatively small profits and profit margins in the augmentative biological control industry.

Summary of Specific Features of Biological Control. ABS regulations should recognize the specific features of biological control: countries providing BCAs are also themselves users of this technology; many BCAs are exchanged, but have little recoverable monetary value; organisms are not patented, so can be used by anyone at any time; classical biological control information and to a degree augmentative biological control information are publicly shared; there are societal benefits for all, such as environmental and public health benefits, and reduction in pesticide use; Biological control is widely used in both developing and developed countries, often using the same BCAs; most use of biological control relates to food and agriculture.

Recommendations. In view of these specific positive features, the following recommendations are made:

1. Governments should build on the existing multilateral practice of exchange of natural enemies for biological control on a complementary and mutually reinforcing basis, which ensures fair and equitable sharing of the benefits of biological control worldwide.

2. ABS regulations should encourage further development of the biological control sector, by facilitating the multilateral exchange of BCAs.

3. Countries are encouraged to have a single point of contact to facilitate survey missions, provision of information, 
institutional linkages and taxonomic support, and provide advice on compliance with regulations for biological control, including ABS.

4. ABS in relation to biological control will normally be based on non-monetary benefit sharing, e.g. capacity building, shared research programmes and/or technology transfer, as already practised by many organizations and the augmentative biological control industry.

5. A document describing best practices for ABS in relation to biological control, including guidelines for joint research that are equitable but not restrictive, should be prepared and disseminated. Biological control organizations would be expected to follow these guidelines.

6. To improve transparency in the exchange of BCAs, mechanisms should be supported globally to establish and allow free access to database information on BCAs including source and target countries, e.g. BCANZ in New

Post Scriptum: The Nagoya protocol, biological control and access and benefit-sharing.

The Convention on Biological Diversity's access and benefit sharing protocol was agreed on the tenth Conference of Parties to the CBD at Nagoya, Japan, in October last year, and is now known as the Nagoya Protocol (UN. 2010. Nagoya Protocol on Access to Genetic Resources and the Fair and Equitable Sharing of Benefits Arising from their Utilization to the Convention on Biological Diversity. http://treaties. un.org/doc/source/signature/2010/Ch-XXVII-8-b.pdf).

The Nagoya protocol is an agreement between the signatory countries of the CBD as to how access and benefit sharing of genetic resources (including all biological control agents) will be handled in future. Based on this protocol, each country will prepare its own legislation and regulations. Article 8 'Special Considerations' of the Nagoya Protocol states:

"In the development and implementation of its access and benefit-sharing legislation or regulatory requirements, each Party shall:

(a) Create conditions to promote and encourage research which contributes to the conservation and sustainable use of biological diversity, particularly in developing countries,' including through simplified measures on access for non-commercial research purposes, taking into account the need to address a change of intent for such research;

(b) Pay due regard to cases of present or imminent emer-
Zealand (Ferguson et al. 2007).

7. In the case of a humanitarian or an emergency situation for food security, governments should cooperate within FAO to fast track action in the exchange of BCAs.

\section{REFERENCES}

Cock, M. J. W.; J. C. van Lenteren; J. Brodeur; B. I. P. Barratt; F. Bigler; K. Bolckmans; F. L. Cônsoli; F. Haas; P. G. Mason \& J. R. P. Parra. 2009. The use and exchange of biological control agents for food and agriculture. FAO Background Study No. 47, FAO, Rome: 88 p.

Cock, M. J. W.; J. C. van Lenteren; J. Brodeur; B. I. P. Barratt; F. Bigler; K. Bolckmans; F. L. Cônsoli; F. Haas; P.G. Mason \& J. R. P. Parra. 2010. Do new Access and Benefit Sharing procedures under the Convention on Biological Diversity threaten the future of Biological Control? BioControl 55: 199-218.

Ferguson C.M.; A. Moeed; B.I.P. Barratt; R.L. Hill \& J.M. Kean. 2007. BCANZ - Biological Control Agents introduced to New Zealand. Available from: http://www.b3nz.org/bcanz (accessed March 2011).

gencies that threaten or damage human, animal or plant health, as determined nationally or internationally. Parties may take into consideration the need for expeditious access to genetic resources and expeditious fair and equitable sharing of benefits arising out of the use of such genetic resources, including access to affordable treatments by those in need, especially in developing countries;

(c) Consider the importance of genetic resources for food and agriculture and their special role for food security."

If it is accepted that biological control is non-commercial research, simplified measures for access and benefit sharing should facilitate biological control research. Furthermore, the use of biological control to address emergencies and the needs of food and agriculture should also be facilitated. However, in practice, a lot will depend on the legislation and regulations put in place by each country, and there is still a risk that if biological control is not accepted as non-commercial research in this process, some countries may inadvertently make it unnecessarily difficult or even impossible to access biological control agents. The biological control community in each country is encouraged to have an input into the legislation and regulation process to encourage the facilitation of biological control along with other non-commercial research activities, e.g. relating to taxonomy, ecology and conservation. 